the second more attractive because, unlike the first, it is based on analogy with facts which have actually been observed.

John Innes Horticultural Institution, J. B. S. HALdANE. Merton Park, London, S.W.19, June 17.

${ }^{1}$ Bridges and Morgan: Carnegie Inst. Pub. 327.

In the above letter, Mr. Haldane misinterprets the theory of the origin of Gastropoda as a consequence of the sagging of the visceral hump to one side. The sagging of the visceral hump no more 'injured' the ancestral molluse than does the weight of her protuberant abdomen a pregnant woman. It continually stimulated the skin of one side by stretching it, and what was transmitted to posterity was not the passive stretching but the altered habit of growth called forth in response to it. That such altered habits of growth do become hereditary has been proved by every relevant experiment on the subject. As I have said elsewhere, Przibram enumerated at least six examples of this. I have just returned from a northern university where pioneering genetical research is going on. I think it probable that in the near future Przibram's six examples will become at least ten.

Mr. Haldane instances a Drosophila with distorted abdomen as giving an example of the sudden miraculous mutation which De Beer postulated as the origin of the Gastropoda. He admits that this individual was so enfeebled that it would not mate, much less give rise to offspring. He overlooks the fact that the want of viability of the mutants of Drosophila is in direct proportion to their divergence from the type; and the idea that an enfeebled mutant would be preserved by 'natural selection' when all its normal bilaterally symmetrical fellows perished is one that cannot be entertained. No competent systematist, palæontologist, or embryologist would agree with Mr. Haldane, and it is these people who have the final word on the causes and course of evolution.

Royal College of Science,

E. W. MacBride.

South Kensington, S.W.7, June 23.

The Position of Fundamental Research.

IN the interesting leading article in NATURE of May 31, a lament is sounded that pure research of the kind fostered in colleges and universities is no longer able to attract the best of the younger scientific students. The cause is attributed to the relatively poor salaries which colleges can offer; and this opinion is substantiated by comparison between the financial rewards of commerce and industry on one hand, and of the teaching and research profession on the other.

Although lack of money may be a powerful contributory reason, it would seem that the real cause of the shortage lies deeper. Surely pure research is done best by persons who are inspired in their work, and supported best by institutions to whom their work is useful.

The universities fostered research because teachers could not, in general, remain in the forefront of their respective fields unless they were creating as well as retailing knowledge. It was recognised that research was necessary to inspire teaching; and later the interesting belief became common that teaching, with its continual summarising of existing. knowledge, its regular routine, and the stimulus of irksome duties and of question and of answer, was equally necessary to fertilise research. That was when the preponder- ance of scientific knowledge was situated within the university campus.

At the present time much of scientific learning is housed within the walls of industry, and it is to industry that even your pure scientist looks for the greatest inspiration. Industry in America has known for years that works laboratories stocked with technicians, inventors, and trouble tracers soon become sterile unless pure research, with its right to publish and its consequent prestige to the individual, is carefully fostered. 'This does not mean necessarily that a few privileged persons are permitted to pioneer scientifically in a building where others are kept strictly to the kind of work bearing immediate profit. It means often that those who have the mental equipment use part of their time on industrial problems, part in pursuit of their scientific hobby-pure research. One has only to eite Langmuir's work on adsorption, Sheppard's discoveries in photographic sensitivity, or the scientific publications of the Bell Telephone Laboratories, to see how amazingly industry has stimulated scientific minds in the pursuit of knowledge for its own sake.

The old academic'feeling that there was something vaguely discreditable in a discovery which could be put to practical use is passing. Those who love knowledge for its own sake now often have the double satisfaction of securing an advance of understanding, and at the same time seeing this advance aiding the manufacture of some product in enormous quantities.

The tragedy, one feels, is not that the colleges can no longer attract young men for research, but that they cannot provide the whole environment of research, leisure, and remuneration which is necessary to secure the best men to train those other keen young scientists who will later find their opportunity in the industrial research laboratories.

K. HICKMaN.

Eastman Kodak Company,

Research Laboratories,

Rochester, N.Y.

\section{Triatomic Hydrogen.}

IN recent years various observers have investigated the formation of active hydrogen in discharge tubes at pressures ranging from two centimetres to atmospheric. The evidence has been both positive and negative.

In the formation of atomic hydrogen by $\mathbf{R}$. W. Wood's method, it is considered that the water vapour poisons the glass walls and prevents the reversion to molecular hydrogen. Lewis (Jour. Am. Chem. Soc., 51, $654 ; 1929)$, in a study of the influence of surface upon the after glow in nitrogen, found that water vapour or paraffin poisoned the walls of the glass bulb to such an extent that the life period of the glow was doubled or tripled.

A study has been made of the influence of surface upon the formation of triatomic hydrogen based upon Wood's theory. We have repeated the work of Urey and Smallwood (Jour. Am. Chem. Soc., 50, 620; 1928) dealing with corona and vacuum tube discharges. We find that their results are correct under their experimental conditions. No appreciable activation of hydrogen is observed. However, when we introduced a trace of oxygen before the gas mixture reached the discharge tube, the results were positive as shown by the lead sulphide formed on the lead acetate paper.

To test Wood's theory still further, we poisoned the walls of the discharge tube with stearic acid and omitted the oxygen from the stream of pure hydrogen. The results were again positive, showing that hydrogen is activated in discharge tubes above $2 \mathrm{~cm}$. pressure. During the latter part of this work, fresh plastic

No. 3166 , VoL. 126] 